\title{
Impairment, disability, or handicap in peripheral neuropathy: analysis of the use of outcome measures in clinical trials in patients with peripheral neuropathies
}

\author{
D S M Molenaar, $R$ de Haan, $M$ Vermeulen
}

\begin{abstract}
Outcome measures can be classified into measures of impairment, disability, and handicap. To investigate the biological effect of treatment, measures of impairment are appropriate. Studies investigating whether patients benefit from treatment in terms of improvement of functional health, however, require disability or handicap measures.

In a review of the medical literature between 1978 and 1993, 73 controlled intervention studies in patients with peripheral neuropathies were found. Disability or handicap measures were used in two of 54 studies in patients with diabetic neuropathy, in two of six studies in patients with chronic inflammatory demyelinating polyneuropathy, in none of five studies in a mixed group of patients, and in all eight studies in patients with Guillain-Barré syndrome.

The limited use of disability and handicap measures in patients with diabetic and mixed neuropathies can be explained by the experimental nature of most studies. In four of six studies, however, in patients with chronic inflammatory demyelinating polyneuropathy or neuropathy associated with monoclonal gammopathy that were designed to assess effectiveness of treatment, the choice of outcome measures was not appropriate. It is concluded that in the design of intervention studies in patients with peripheral neuropathy more attention should be paid to a proper choice of suitable outcome measures to assess the effectiveness of treatment.
\end{abstract}

(F Neurol Neurosurg Psychiatry 1995;59:165-169)

Departmen

D S M Molenaar

$M$ Vermeulen

Department of Clinical

Epidemiology and

Biostatistics,

Academic Medical

Centre, University of

Amsterdam,

Amsterdam, The

Netherlands

$\mathbf{R}$ de Haan

Correspondence to:

Dr D S M Molenaar,

Department of Neurology

(H2-214), Academic

Medical Centre, PO Box

$22700,1100 \mathrm{DE}$

Amsterdam, The

Netherlands.

Received 19 December 1994

and in revised form

13 March 1995.

Accepted 16 March 1995

Keywords: treatment outcome; peripheral nervous system diseases; randomised controlled trial

Disorders of peripheral nerves can cause weakness and sensory disturbances. Symptoms range from pure sensory to pure motor, and from slight numbness and weakness in patients with chronic idiopathic axonal neuropathy to complete loss of muscle strength including the respiratory muscles in Guillain-Barré syndrome. Therefore, the effectiveness of medical treatment in different neuropathies is assessed by different outcome measures. For example, in diabetic neuropathy there is a focus on sensory signs, which are measured with thermal and vibration perception thresholds, whereas in Guillain-Barré syndrome the focus is on the assessment of muscle weakness.

The choice of an outcome measure should not, however, depend on whether the neuropathy is predominantly sensory or motor. More important is the question the investigator wishes to answer, because this question determines the choice of outcome measures. We made a distinction in two types of questions that can be studied in intervention studies: those that concern the biological effects of a treatment-for example, a phase II studyand those that concern the clinical effects of treatment, in, for example, a phase III study. ${ }^{1}$ The second type of questions should preferably be directed to changes in functional health, which is highly relevant for patients.

Outcome measures of clinical trials can be classified according to the model of the consequences of disease developed by the World Health Organisation in $1980 .^{2}$ This model describes three classes: impairment, disability, and handicap. Impairment refers to organ dysfunctions or abnormalities of body structure (for example, numbness, weakness, decreased reflexes, or slowed nerve conduction velocity), disability to the patient's functional performance (for example, walking or eating), and handicap to the social disadvantages resulting from impairment and disability (for example, the ability to work). Although this classification seems to be straightforward, there is confusion about terms. For instance, the neurologic disability score is in fact an impairment measure, because it is a composite of cranial nerve function, reflexes, muscle strength, and sensory disturbances. ${ }^{3}$

The purpose of this study was to analyse the choice of outcome measures in intervention studies on peripheral neuropathies.
Material and methods

By means of a Medline search (keywords: peripheral neuropathy and clinical trial, limited to English language, humans, and abstracts) and reference tracing we collected intervention studies published between January 1978 and December 1993.

We ordered the outcome measures used in these studies into pathology, impairment, disability, handicap, and subjective health. Pathology was defined as an abnormality of macroscopic, microscopic, or biochemical structure occurring within the cells of an organ or organ system. This definition is 
Table 1 Outcome measures and instruments to assess treatment outcome in studies on peripheral neuropathies, classified in terms of pathology, impairment, disability, handicap, and perceived health

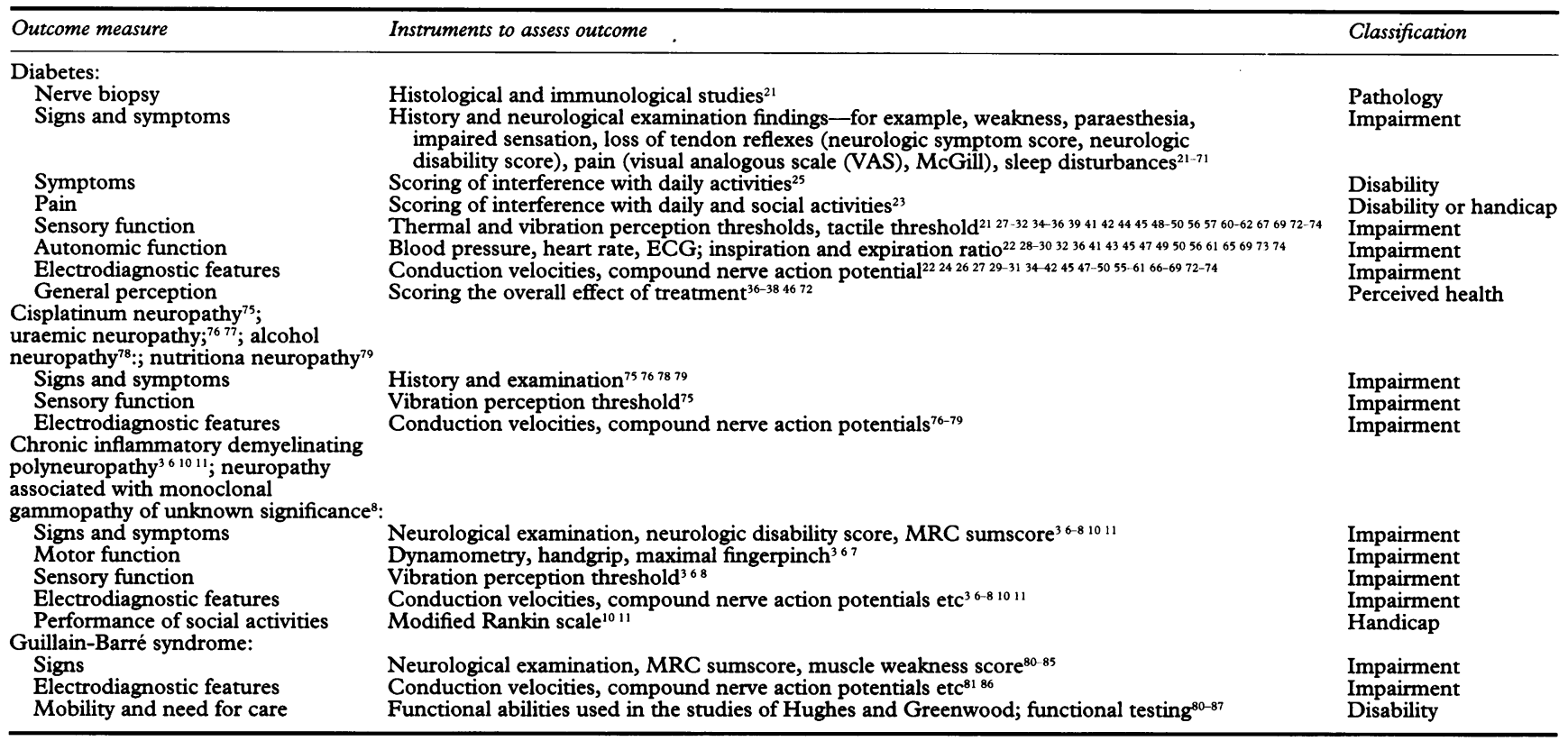

synonymous with disease and usually with diagnosis. ${ }^{4}$ According to our classification, a nerve biopsy was considered to be a measure of pathology. Neuropathic signs and symptoms (weakness, pain, paraesthesia, numbness, impaired sensation, and areflexia), as well as quantified motor, sensory, and autonomic function tests, and electrophysiological tests were classified as measures of impairment. We considered the need for care and performance of daily activities as measures of disability, whereas social performance scales were regarded as measures of handicap. Finally, scales that assessed the overall subjective effect of treatment were categorised as instruments focusing on perceived health. ${ }^{5}$

\section{Results}

We collected 73 randomised controlled intervention studies of which 54 were studies on diabetic peripheral neuropathies, eight on Guillain-Barré syndrome, five on chronic inflammatory demyelinating polyneuropathy, two on uraemic polyneuropathy, and one each on peripheral neuropathy associated with monoclonal gammopathy of undetermined significance, cisplatinum neuropathy, alcohol neuropathy, and nutritional neuropathy. The studies were assigned to four groups: diabetic neuropathies, Guillain-Barré syndrome, chronic inflammatory demyelinating polyneuropathy, or neuropathy associated with monoclonal gammopathy of undetermined significance, and mixed neuropathies.

Table 1 presents the different types of outcome measures used to assess efficacy. Outcome measures and their instruments are classified in terms of pathology, impairment, disability, handicap, and perceived health.

Table 2 shows the frequency with which the different classes were assessed for the four groups of neuropathies. All studies on patients with diabetic neuropathies, with mixed neuropathies, and with chronic inflammatory demyelinating polyneuropathy focused on the assessment of impairment. In patients with Guillain-Barré syndrome impairment was assessed in six of eight studies. Disability or handicap measures were used in two of 54 studies on patients with diabetic neuropathy, in two of six studies on patients with chronic inflammatory demyelinating polyneuropathy, in none of five studies in a mixed group of patients, and in all eight studies on patients with Guillain-Barré syndrome. Perceived health was scored in five studies on patients with diabetic neuropathy.

\section{Discussion}

This current study was undertaken to analyse

Table 2 Frequencies of treatment outcomes in terms of pathology, impairment, disability, handicap, and perceived health in studies on peripheral neuropathies

\begin{tabular}{llllll}
\hline & \multicolumn{2}{l}{ Classification } & & & \\
\cline { 2 - 6 } Neuropathy (n) & Pathology & Impairment & Disability & Handicap & Perceived health \\
\hline Diabetes (4) & 1 & 54 & 1 & 1 & 5 \\
Mixed (5) & 0 & 5 & 0 & 0 & 0 \\
CIDP; MGUS (6) & 0 & 6 & 0 & 2 & 0 \\
Guillain-Barré syndrome (8) & 0 & 6 & 8 & 0 & 0
\end{tabular}

$\mathrm{n}=$ Number of studies; CIDP = chronic inflammatory demyelinating polyneuropathy; MGUS = monoclonal gammopathy of unknown significance. 
the choice of outcome measures in intervention studies on peripheral neuropathies. The results show that in our reviewed patient groups different outcome measures were used. In patients with diabetes and mixed neuropathies mainly impairment measures have been used to investigate effectiveness of treatment. This is by contrast with studies in patients with Guillain-Barré syndrome, which all used disability measures. Studies in chronic inflammatory demyelinating polyneuropathy or neuropathy associated with monoclonal gammopathy of undetermined significance used either impairment measures or both impairment and handicap measures.

How to explain these differences? First of all, as has been noted previously, there is a difference in questions to be answerednamely, has the treatment a biological effect or a clinical effect? With the second question treatment recommendation is, of course, strongly supported if the concerning intervention is actually improving the functional health of the patients. Treatment in diabetic neuropathy is still in an early experimental stage. The aim in most studies is to investigate if there is any effect at all on the disease process. If there is an effect, however small this may be, this supports the hypothesis that the treatment has some biological effect. Studies such as these increase our knowledge of the disease process itself. To investigate hypotheses about the pathogenesis we therefore need the most sensitive measures because we do not wish to miss even the smallest changes. In these cases impairment measures, which assess disturbed function of peripheral nerves, are the best measures. For as long as there is no satisfactory treatment available in diabetic neuropathy, experimental studies incorporating impairment measures must continue.

In patients with Guillain-Barré syndrome the situation is different. These patients usually improve spontaneously; they may need respiratory support and are unable to walk for some variable period of time. If an experimental treatment showed improved nerve conduction velocities, compound muscle action potentials, or strength, clinicians would immediately ask whether there was a difference in the number of patients who needed respiratory support, differences in time spent on the respirator, differences in time spent in the hospital, or differences in the ability to walk. This kind of information is usually provided by disability measures, which show whether the treatment has a beneficial effect on the patient's functional health. Such information improves clinical decision making.

Yet we do not think that the questions, whether a treatment works biologically or whether it has a clinical effect in terms of functional health, fully explain the use of different outcome measures. In studies on chronic inflammatory demyelinating polyneuropathy and neuropathy associated with monoclonal gammopathy of undetermined significance, all interventions were evaluated with impairment measures, whereas only two studies used handicap scales as well. In the discussion of the results of four studies that focused on impairment measures, the authors did not comment on how results of trials with this kind of measures should be interpreted. ${ }^{36-8}$ Instead of concluding that the results were encouraging and that other studies, using disability or handicap measures, should be initiated to answer the question whether functional health of patients improves as a result of treatment, treatment recommendations were already presented. The other two studies on chronic inflammatory demyelinating polyneuropathy used the Rankin scale. ${ }^{9-11}$ Although the Rankin scale was considered as a measure of handicap, ${ }^{12}$ it has a strong association with physical disability. ${ }^{1314}$ Therefore, this scale is not a pure handicap measure. Nevertheless, whether it assesses handicap or disability does not alter the fact that it can be used as an efficient global functional health index.

Just as in the discussion of the results of most chronic inflammatory demyelinating polyneuropathy trials, the differences between impairment and disability or handicap measures remained unnoticed in the published recommendations of the consensus meeting on standards in diabetic neuropathy. ${ }^{15}$ In the recommendations emphasis was laid on sensitivity and objectivity of measurements. The authors stressed that because of the relative subjectivity and imprecision of the clinical measures, defined as the medical and neurological history and physical examination, confirmation by more objective measures such as electrodiagnostic, quantitative sensory and autonomic function, or morphometric tests is required. These tests measure pathology or impairment. Objectivity is without doubt important. Objective measurement by electrophysiological methods of, for instance, compound muscle action potentials, may be of less clinical value, however, than a scale scoring the daily activities of a patient, provided that the reliability and validity of such a scale has been investigated and found acceptable. Of the disability and handicap scales, as used in the reviewed studies, only the functional abilities of the Hughes and Rankin scale have been investigated on reliability and validity. ${ }^{12} 1617$ To our surprise, the option of functional measures were not considered in the recommendations of the consensus meeting on standards in diabetic neuropathy. Certainly, from the patient's point of view changes in functional health as a result of treatment are of major importance and should therefore be evaluated. Moreover, the question whether improvement is negatively influenced by side effects of treatment cannot be answered by using impairment scores.

Within other fields of neurology the different levels of measurement outlined have been recognised. ${ }^{1819}$ Most intervention studies in patients with stroke use disability measures these days. ${ }^{13}$ The older Matthew scale, which is partly comparable with the so called neurologic disability score recommended for patients with diabetic neuropathy, has been 
abandoned. In studies on brain trauma the importance of measuring disability has generally been accepted (for example, the Glasgow outcome scale)..$^{20}$

We believe that impairment measures give information on the biological effect of treatment, whereas disability and handicap measures give clinically important and patient relevant information showing whether a treatment improves the patient's functional health. Treatment recommendations should be based on trials in which disability and handicap are assessed, not on trials in which impairment only is assessed. There might be an exception for studies with negative results using impairment measures: if a treatment has no biological effect, it will usually not improve functional health.

In conclusion, in the design of intervention studies in patients with peripheral neuropathies more attention should be paid to a proper choice of outcome measures to assess the effectiveness of treatment.

1 Altman DG. Clinical trials. In: Altman DG, ed. Practical statistics for medical research. London: Chapman and

2 World Health Organisation. International classification of impairments, disabilities and handicaps. Geneva: WHO, 1980

3 Dyck PJ, O'Brien PC, Oviatt KF, et al. Prednisone improves chronic inflammatory demyelinating polyradiculoneuropathy more than no treatment. Ann Neurol 1982;11:136-41.

4 Wade DT. Measurement in neurological rehabilitation. Oxford: Oxford University Press, 1992.

5 de Haan R, Aaronson N, Limburg M, Hewer RL, van Crevel $\mathrm{H}$. Measuring quality of life in stroke. Stroke 1993;24:320-7.

6 Dyck PJ, Daube I, O'Brien P, et al. Plasma exchange in chronic inflammatory demyelinating polyradiculoneuropathy. $N$ Engl ₹ Med 1986;314:461-5.

Dyck PJ, O'Brien P, Swanson C, Low P, Daube J. Combined azathioprine and prednisone in chronic inflammatory-demyelinating polyneuropathy. Neurology 1985;35:1173-6.

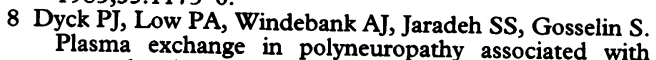
monoclonal undetermined significance. $N$ Engl $f$ Med

9 Rankin J. Cerebral vascular accidents in patients over the age of 60. II. Prognosis. Scott Med F 1957;2:200-15.

10 van Doorn PA, Brand A, Strengers PF, Meulstee J Vermeulen M. High-dose intravenous immunoglobuli treatment in chronic inflammatory demyelinating
polyneuropathy: a double-blind, placebo-controlled,
crossover study. Neurology 1990;40:209-12.

11 Vermeulen M, van Doorn PA, Brand A, Strengers PF, Jennekens FG, Busch HF. Intravenous immunoglobulin treatment in patients with chronic inflammator demyelinating polyneuropathy: a double blind, placebo controlled study. F Neurol Neurosurg Psychiatry 1993;56: 36-9.

12 van Swieten JC, Koudstraal PJ, Visser MC, Schouten HJA, van Gijn J. Interobserver agreement for the assessment of handicap in stroke patients. Stroke 1988;19: 13 de Haan R. Clinimetrics in stroke. Amsterdam: University

14 Visser MC, Koudstaal PJ, van Latum JC, Frericks $H$, Berengholz-ZSN, van Gijn J. Interobserver variation in the application of 2 disability scales in heart patients. [English abstract]. Ned Tijdschr Geneeskd 1992;136: 831-4.

15 Anonymous. Proceedings of a consensus development conference on standardized measures in diabetic neuropathy. Summary and recommendations. Neurology 1992; 42:1837-9

16 Kleyweg RP, van der Meche FG, Schmitz PI Interobserver agreement in the assessment of muscle strength and functional abilities in Guillain-Barre syndrome. Muscle Nerve 1991;14:1103-9.

17 de Haan R, Horn J, Limburg M, Van Der Meulen J, Bossuyt P. A comparison of five stroke scales with measures of disability, handicap, and quality of life.
Stroke 1993;24:1178-81.

18 McDowell I, Newell C. Measuring health: a guide to rating scales and questionnaires. Oxford: Oxford University

19 Munsat TL. Quantification of neurologic deficit. Stoneham MA: Butterworths, 1989.
20 Jennett B, Bond MR. Assessment of outcome after severe

21 Sima AA, Bril V, Nathaniel V, McEwen TA, Brown MB, Lattimer SA. Regeneration and repair of myelinated fibers in sural-nerve biopsy specimens from patients with diabetic neuropathy treated with sorbinil. N Engl F Med
1988;319:548-55.

22 Abraham RR, Abraham RM, Wynn V. A double blind placebo controlled trial of mixed gangliosides in diabetic peripheral and autonomic neuropathy. Adv Exp Med Biol 1984;174:607-24.

23 Anonymous. Effect of treatment with capsaicin on daily activities of patients with painful diabetic neuropathy.

24 Boulton AJ, Levin S, Comstock J. A multicentre trial of the aldose-reductase inhibitor, tolrestat, in patients with symptomatic diabetic neuropathy. Diabetologia 1990;33 431-7.

25 Cohen KL, Harris S. Efficacy and safety of nonsteroidal anti-inflammatory drugs in the therapy of diabetic neuropathy. Arch Intern Med 1987;147:1442-4.

26 Crepaldi G, Fedele D, Tiengo A, et al. Ganglioside treatment in diabetic peripheral neuropathy: a multicenter trial. Acta Diabetol 1983;20:265-76.

27 De Leeuw IH, Van Rooy P, Moeremans M, Driessens M. Clinical experience with cyclandelate in insulin-dependent diabetic patients with neuropathy. Drugs 1987;33 (suppl 2):125-30.

28 Dejgard A, Petersen P, Kastrup J. Mexiletine for treatment of chronic painful diabetic neuropathy. Lancet 1988;ii:

29 Fagius J, Brattberg A, Jameson S, Berne C. Limited benefit of treatment of diabetic polyneuropathy with an aldose reductase inhibitor: a 24-week controlled trial. Diabetologia 1985;28:323-9.

30 Fagius J, Jameson S. Effects of aldose reductase inhibitor treatment in diabetic polyneuropathy: a clinical and neurophysiological study. Neurol Neurosurg Psychiatry 1981;
44:991-1001.

31 Florkowski CM, Rowe BR, Nightingale S, Harvey TC, Barnett AH. Clinical and neurophysiological studies of aldose reductase inhibitor ponalrestat in chronic symptomatic diabetic peripheral neuropathy. Diabetes 1991; 40:129-33.

32 Gill JS, Williams G, Ghatei MA, Hetreed AH, Mather HM, Bloom SR. Effect of the aldose reductase inhibitor, ponalrestat, on diabetic neuropathy. Diabetes Metab Rev 1990;16:296-302.

33 Gomez-Perez FJ, Rull JA, Dies H, Rodriquez-Rivera JG, Lozano-Castaneda $\mathrm{O}$. Nortriptyline and fluphenazine in the symptomatic treatment of diabetic neuropathy. A double-blind cross-over study. Pain 1985;23:395-400.

34 Goto Y, Hotta N, Shigeta Y, et al. A placebo-controlled double-blind study of epalrestat (ONO-2235) in patients with diabetic neuropathy. Diabet Med 1993;10(suppl 2:39S-43S.

35 Gregersen G, Borsting H, Theil P, Servo C. Myoinositol and function of peripheral nerves in human diabetics. A controlled clinical trial. Acta Neurol Scand 1978;58: 241-8.

36 Guy RJ, Gilbey SG, Sheehy M, Asselman P, Watkins PJ. Diabetic neuropathy in the upper limb and the effect of twelve months sorbinil treatment. Diabetologia 1988;31: twelve $214-20$.

37 Hallett $M$, Flood T, Slater N, Dambrosia J. Trial of ganglioside therapy for diabetic neuropathy. Muscle Nerve 1987;10:822-5.

38 Handelsman DJ, Turtle JR. Clinical trial of an aldose reductase inhibitor in diabetic neuropathy. Diabetes 1981;30:459-64.

39 Heimans J, Drukarch B, Matthaei I, Ijff GA, Bertelsmann FW. Cyclandelate in diabetic neuropathy. A doubleblind, randomized, cross-over study. Acta Neurol Scand 1991;84:483-6.

40 Horowitz SH. Ganglioside therapy in diabetic neuropathy. Muscle Nerve 1986;9:531-6.

41 Hotta N, Kawamori R, Sano T, Kakuta H, Kamada T Sakamoto N. Diabetic neuropathy: effects of intensified glycaemic control with multiple insulin injections. Diabe Med 1993;10(suppl 2):91S-4S.

42 Jamal GA, Carmichael $H$. The effect of gamma-linolenic acid on human diabetic peripheral neuropathy: a double-blind placebo-controlled trial. Diabet Med 1990; 7:319-23.

43 Jaspan J, Maselli R, Herold K, Bartkus C. Treatment of severely painful diabetic neuropathy with an aldose reductase inhibitor: relief of pain and improved somatic and autonomic nerve function. Lancet 1983;ii:758-62.

44 Kastrup J, Petersen P, Dejgard A, Angelo HR, Hilsted J. Intravenous lidocaine infusion-a new treatment $\mathrm{J}$. chronic painful diabetic neuropathy? Pain 1987;28: 69-75.

45 Keen H, Payan J, Allawi J, et al. Treatment of diabetic neuropathy with gamma-linolenic acid. The gammalinolenic acid multicenter trial group. Diabetes Care 1993;16:8-15.

46 Kvinesdal B, Molin J, Froland A, Gram LF. Imipramine treatment of painful diabetic neuropathy. $\mathcal{F} A M A 1984$; :1727-30.

47 Lewin IG, O'Brien IA, Morgan MH, Corrall RJ. Clinical and neurophysiological studies with the aldose reductase inhibitor, sorbinil, in symptomatic diabetic neuropathy. Lehtinen JMa 1984;26:445-8.

Halonen T. The effect of sorbinil treatment on red cell 
sorbitol levels and clinical and electrophysiological parameters of diabetic neuropathy. $\mathcal{F}$ Neurol 1986;233:174-7.

49 Liniger C, Pernet A, Moody JF, Assal JP. Effect of gangliosides on diabetic peripheral neuropathy. Diabetes Res Clin Prac 1989;7:251-8.

50 Martyn CN, Reid W, Young RJ, Ewing DJ, Clarke BF. Six-month treatment with sorbinil in asymptomatic diabetic neuropathy. Failure to improve abnormal nerve function. Diabetes 1987;36:987-90.

51 Max MB, Culnane M, Schafer SC, Gracely RH, Walther DJ, Smoller B. Amitriptyline relieves diabetic neuropathy pain in patients with normal or depressed mood. Neurology 1987;37:589-96.

52 Max MB, Lynch SA, Muir J, Shoaf SE, Smoller B, Dubner R. Effects of desipramine, amitriptyline, and fluoxetine on pain in diabetic neuropathy [see comments]. N Engl f Med 1992;326:1250-6.

53 Max MB, Kishore-Kumar R, Schafer SC, Meister B, Gracely RH. Efficacy of desipramine in painful diabetic
neuropathy: a placebo-controlled trial. Pain 1991;45: neuropat.

54 Mendel CM, Klein RF, Chappell DA, et al. A trial of amitriptyline and fluphenazine in the treatment of painful diabetic neuropathy. $\mathscr{f} A M A$ 1986;255:637-9.

55 Naarden A, Davidson J, Harris L, Moore J, DeFelice S. Treatment of painful diabetic polyneuropathy with mixed gangliosides. Adv Exp Med Biol 1984;174:581-92.

56 O'Hare JP, Morgan MH, Alden P, Chissel S, O'Brien IA Corrall RJ. Aldose reductase inhibition in diabetic neuropathy: clinical and neurophysiological studies of one year's treatment with sorbinil. Diabet Med 1988;5: 537-42.

57 Sachse G, Willms B. Efficacy of thioctic acid in the therapy of peripheral diabetic neuropathy. Horm Metab Res Suppl 1980;9:105-7.

58 Salway JG, Whitehead L, Finnegan JA, Karunanayaka A, Barnett D, Payne RB. Effect of myo-inositol on peripheral-nerve function in diabetes. Lancet 1978;ii:1282-4.

59 Santiago JV, Snksen PH, Boulton AJ, et al Withdrawal of the aldose reductase inhibitor tolrestat in patients with diabetic neuropathy: effect on nerve function. The Tolrestat Study Group. $\mathcal{F}$ Diabetes Complications 1993;7: 170-8.

60 Sindrup SH, Ejlertsen B, Froland A, Sindrup EH, Brosen K. Gram. Imipramine treatment in diabetic neuropathy: relief of subjective symptoms without changes in peripheral and autonomic nerve function. Eur $f$ Clin Pharmacol 1989;37:151-3.

61 Sindrup SH, Gram LF, Brosen K, Eshoj O, Mogensen EF. The selective serotonin reuptake inhibitor paroxetine is effective in the treatment of diabetic neuropathy tine is effective in the treatment
symptoms. Pain 1990;42:135-44.

62 Sindrup SH, Gram LF, Skjold T, Grodum E, Brosen K, Beck-Nielsen H. Clomipramine vs desipramine vs placebo in the treatment of diabetic neuropathy symptoms. A double-blind cross-over study. $\mathrm{Br} \mathscr{f} \mathrm{Clin}$ Pharmacol 1990;30:683-91.

63 Sindrup SH, Tuxen C, Gram LF, Grodum E, Skjold T, Brosen $\mathrm{K}$. Lack of effect of mianserin on the symptoms of diabetic neuropathy. Eur $\mathcal{f}$ Clin Pharmacol 1992;43: 251-5.

64 Sindrup SH, Bierre U, Deigaard A, Brosen K, AaesJorgensen T, Gram LF. The selective serotonin reuptake inhibitor citalopram relieves the symptoms of diabetic neuropathy. Clin Pharm Ther 1992;52:547-52.

65 Stracke H, Meyer UE, Schumacher HE, Federlin K Mexiletine in the treatment of diabetic neuropathy. Mexiletine in the treatment
Diabetics Care 1992;15:1550-5.

66 Toyota T, Hirata Y, Ikeda Y, Matsuoka K, Sakuma A, Mizushima Y. Lipo-PGE1, a new lipid-encapsulated preparation of prostaglandin E1: placebo- and prostaglandin E1-controlled multicenter trials in patients with diabetic neuropathy and leg ulcers. Prostaglandins 1993;46:453-68.
67 van Gerven JM, Lemkes HH, van Dijk JG. Long-term effects of tolrestat on symptomatic diabetic sensory polyneuropathy. 7 Diabetes Complications 1992;6:45-8.

68 Yaqub BA, Siddique A, Sulimani R. Effects of methylcobalamin on diabetic neuropathy. Clin Neurol Neurosurg 1992;94:105-11.

69 Young RJ, Ewing DJ, Clarke BF. A controlled trial of sorbinil, an aldose reductase inhibitor, in chronic painful diabetic neuropathy. Diabetes 1983;32:938-42.

70 Young RJ, Clarke BF. Pain relief in diabetic neuropathy: the effectiveness of imipramine and related drugs. Diabet Med 1985;2:363-6.

71 Zeigler D, Lynch SA, Muir J, Benjamin J, Max MB. Transdermal clonidine versus placebo in painful diabetic neuropathy. Pain 1992;48:403-8.

72 Christensen JE, Varnek L, Gregersen G. The effect of an aldose reductase inhibitor (Sorbinil) on diabetic neuropathy and neural function of the retina: a double-blind study. Acta Neurol Scand 1985;71:164-7.

73 Sundkvist G, Armstrong FM, Bradbury JE, et al. Peripheral and autonomic nerve function in 259 diabetic patients with peripheral neuropathy treated with ponalpatients with peripheral neuropathy treated with ponalrestat (an aldose reductase inhibitor) or placebo for 18 months. United Kingdom/Scandinavian Pon

74 Ziegler D, Mayer P, Rathmann W, Gries FA. One-year treatment with the aldose reductase inhibitor, ponalrestat, in diabetic neuropathy. Diabetes Res Clin Pract 1991;14:63-73.

75 van der Hoop RG, Vecht CJ, van der Burg ME, et al. Prevention of cisplatin N Engl f Med 1990;322:89-94.

76 Dukanovic L, Petrovic J, Potic J. Middle molecular weight substances and uremic polyneuropathy. Acta Med Lugosl 1990;44:117-28.

77 Sprenger KB, Bundschu D, Lewis K, Spohn B, Schmitz J, Franz HE. Improvement of uremic neuropathy and hypoguesia by dialysate zinc supplementation: a doubleblind study. Kidney Int 1993;16(suppl):315-8.

78 Mamoli B, Brunner G, Mader R, Schanda H. Effects of cerebral gangliosides in the alcoholic polyneuropathies. Eur Neurol 1980;19:320-6.

79 Djoenaidi W, Notermans SL. Thiamine tetraphydrofurfuryl disulfide in nutritional polyneuropathy. Eur Arch Psychiatry Neurol Sci 1990;239:218-20.

80 French Cooperative Group on Plasma Exchange in Guillain-Barre syndrome. Efficiency of plasma exchange in Guillain-Barre syndrome: role of replacement fluids. Ann Neurol 1987;22:753-61.

81 Greenwood RJ, Newsom-Davis J, Hughes RA, et al. Controlled trial of plasma exchange in acute inflammatory polyradiculoneuropathy. Lancet 1984;i:877-9.

82 Hughes RA, Newsom-Davis JM, Perkin GD, Pierce JM Controlled trial prednisolone in acute polyneuropathy. Lancet 1978;ii:750-3.

83 Mendell JR, Kissel JT, Kennedy MS, et al. Plasma exchange and prednisone in Guillain-Barré syndrome: controlled randomized trial. Neurology 1985;35:1551-5.

84 Osterman PO, Fagius J, Lundemo G, Pihlstedt P, Pirskanen R, Siden A. Beneficial effects of plasma exchange in acute inflammatory polyradiculoneuropathy. Lancet 1984;ii: 1296-9.

85 Van der Meche FG, Schmitz PI. A randomized tria comparing intravenous immune globulin and plasma exchange in Guillain-Barre syndrome. Dutch Guillain-Barre study group. $N$ Engl $\Im$ Med 1992;326: 1123-9.

86 Anonymous. Double-blind trial of intravenous methylprednisolone in Guillain-Barré syndrome. Lancet 1993; 341:586-90.

87 Anonymous. The Guillain-Barré syndrome study group. Plasmapheresis and acute Guillain-Barre syndrome. Neurology 1985;35:1096-104. 